\title{
LA CONTRA CAUTELA. UNA MIRADA DESDE EL ANÁLISIS ECONÓMICO DEL DERECHO PROCESAL
}

\author{
Nicolás CARrasco Delgado* \\ Universidad de Chile
}

\begin{abstract}
RESUMEN: El presente trabajo trata sobre un tema específico de las medidas cautelares: su posibilidad de reemplazo o contra cautela. Al respecto, se estudia cómo debería afrontarse la regulación legal sobre dicha materia de acuerdo al análisis económico del derecho procesal, concluyéndose que la solución que tiende a la eficiencia pasa por robustecer el principio inquisitivo, ya que ello permite tender a la reducción de los costos totales del sistema, aun cuando se afecte la eficacia cuantitativa de la medida, que constituye el valor principalmente resguardado por nuestra legislación prelegislativa contenida en el Anteproyecto de Código de Procedimiento Civil.
\end{abstract}

Palabras clave: Análisis Económico del Derecho, Derecho Procesal, medidas cautelares, contra cautela.

\begin{abstract}
This article discusses prevention measures, specifically possibilities of replacement or when a contractual guarantee is replaced by a superseding guarantee. The article analyses how legal regulation should perform according to Economic Analysis of Procedural Law. Concluding, that the most efficient solution involves strengthening the inquisitorial principle because it lowers total costs of the system. Yet, strengthening the inquisitorial principle impacts the effectiveness of the quantitative measure, that is the main value protected by our pre-legislative law contained in the Draft Code of Civil Procedure.
\end{abstract}

Key words: Economic Analysis of Law, Procedural Law, Interim Measures, Superseding Guarantee.

\section{EL ANÁLISIS ECONÓMICO DEL DERECHO PROCESAL}

De acuerdo con la literatura del análisis económico del derecho procesal, los objetivos que debe buscarse en dicha área jurídica involucra la reducción de dos clases de costes, a saber: la reducción de los costos del sistema judicial y la reducción de los costos del error ${ }^{1}$. Desde dicha perspectiva, una solución eficiente sería aquella que pondere ambas clases de costes, ya que, de esa manera, se obtendría una respuesta óptima.

La búsqueda de dicho equilibrio de eficiencia parte de la premisa de que ambos objetivos, intuitivamente, son contradictorios. En efecto, la búsqueda de una decisión sin error, en el marco de un proceso jurisdiccional regido por la incertidumbre, pasa por aumentar los mecanismos de corrección, lo que, a su vez, significa un incremento de los costos del sistema.

Por otro lado, las exigencias del debido proceso legal constituyen resguardos que no pueden ser soslayados ${ }^{2}$ y que, indudablemente, imponen trámites, diligencias o etapas pro-

\footnotetext{
Abogado Universidad de Chile. Diplomado Procesal Penal Universidad de Chile. Tesista de Magíster con mención en Derecho Económico, Escuela de Graduados, Facultad de Derecho de la Universidad de Chile.

1 Cooter, Robert y Ulen, Thomas. Derecho y Economía. México, DF: Fondo de Cultura Económica, 1998. pp. 530-532, y Posner, Richard. El análisis económico del Derecho. México DF, México: Fondo de Cultura Económica, 1992, pp. 549-551.

2 En este sentido, Cooter y Ulen, cuando señalan: "Las reglas procesales imponen así ciertas restricciones a la toma de deci-
} 
cesales de carácter formal, que acrecientan la inversión en justicia. En este mismo sentido, el proceso es visualizado como mecanismo de adjudicación razonada en virtud de un discurso de adecuación ${ }^{3}$, por lo que la respuesta judicial va asociada a la idea de legitimidad del procedimiento $^{4}$, lo que, comparativamente, resulta más caro que un proceso entendido como simple mecanismo de resolución de conflictos.

Por lo mismo, podríamos pensar que los objetivos del Análisis Económico del Derecho Procesal, resultan ajenos y opuestos a las exigencias que hemos señalado en el párrafo anterior.

Sin embargo, ello no es así, por ejemplo, Richard Posner, implícitamente analiza este problema y consagra una fórmula matemática, tendiente a determinar cuándo se niega el debido proceso a un ciudadano que exige acceso a la justicia, señalando en tal sentido que: "En los términos de la fórmula de $\mathrm{Hand}^{5}$, se niega el proceso debido cuando $\mathrm{B}<\mathrm{PL}$ donde $\mathrm{B}$ es el costo de la salvaguarda procesal, $\mathrm{P}$ es la probabilidad de error si se niega la salvaguarda, y L es la magnitud de la pérdida si se materializa el error"6.

Es importante señalar que la fórmula de Hand, utilizada en materia de responsabilidad civil, pretende determinar cuándo una conducta es negligente, afirmando dicha imprudencia, si la acción se lleva a cabo, en supuestos en que el gasto de previsión (Gp) es menor que daño

siones por parte del tribunal que no serían respetadas por los apostadores profesionales. Las restricciones son casi siempre más estrictas en los países del derecho común cuando los juzgados conocen de casos, que en los países del derecho civil no tienen jurados. En general, un tribunal no falla según que el demandado haya hecho lo que se asevera en la reclamación. Más bien, el tribunal decide si los hechos admitidos por las reglas de procedimiento legal apoyan la reclamación" y "las reglas del procedimiento a veces contradicen a las reglas económicas de la toma de decisiones en incertidumbre, pero existen amplias áreas de acuerdo. Por ejemplo, puede argüirse que si las reglas procesales imponen restricciones a los tribunales, dentro de estas fronteras razonan los jurados y los jueces como personas que toman decisiones económicas racionales. Las reglas procesales prescriben un marco cuya justificación no es necesariamente económica, pero dentro de ese marco puede operar la lógica económica”, en Ibid. p. 483. Para un mayor análisis de esta materia, ver: NOGUEIRA, Humberto. El debido proceso en la Constitución y el sistema interamericano. Santiago, Chile: Editorial Librotecnia, 2007, pp. 42-56.

3 En este sentido, es importante dejar en claro lo que entendemos como discurso de adecuación. Para ello, recurriremos a la exposición que al efecto realiza el profesor Raúl Núñez: "Para nosotros la diferencia se construye a partir de la diferencia entre discurso de fundamentación (o justificación) y discurso de adecuación o de aplicación, como formas discursivas complementarias. El primero tiene por objeto justificar la validez o corrección de una norma, justificación que viene dada por el principio de universalidad. Aun cuando atendido al discurso de justificación o justificación una norma sea válida ello no significa que esa norma deba ser automáticamente aplicada al caso concreto. Es aquí donde entra en juego el discurso de adecuación o aplicación: este discurso se refiere a la corrección de la decisión jurídica, en la cual hay que establecer si la norma prima facie aplicable es adecuada a una situación determinada, para lo que es necesario tener en cuenta todos los datos que caracterizan a esa situación, es decir, la situación de aplicación. La diferencia entre discurso de fundamentación y discurso de aplicación de las normas jurídicas, reside en que el primero es un discurso práctico sobre la validez de las normas independientemente de la situación individual en la que serán aplicadas; mientras que el discurso de aplicación está centrado en la adecuación de las normas a las circunstancias relevantes del caso concreto (aspectos o circunstancias del hecho). Por lo tanto, fundamentación y aplicación son dos formas discursivas complementarias, la primera es labor del Poder Legislativo, y la segunda es propiamente el discurso del órgano jurisdiccional", v. NúÑEZ Ojeda, Raúl. "El sistema de recursos procesales en el ámbito civil en un estado democrático deliberativo", en: Revista Ius et Praxis, vol. 14 No 1, pp. 101-102. Talca, Chile: Universidad de Talca, 2008.

4 TARuffo, Michele. La prueba de los hechos. Milán, Italia: Trotta, 2002, p. 425.

5 La famosa fórmula de Hand fue creada por el juez federal norteamericano Learned Hand, a raíz de su participación en el caso Estados Unidos contra Carroll Towing Co. United States v. Carroll Towing Co., 159 F. 2d 169 (2d Cir. 1947)

6 POSNER, Richard, op. cit. (n. 1), p. 520. 
previsto (D) multiplicado por la probabilidad que ello ocurra $(\mathrm{P})^{7}$. Dicha función se expresa como sigue:

$$
\mathrm{Gp}<\mathrm{D} \times \mathrm{P}^{8}
$$

Aplicando dicha fórmula a la materia aquí tratada, se llega a la conclusión de que se respeta el debido proceso, en materia de acceso a la justicia, si es el caso que un tribunal se niega a dar una audiencia a un sujeto (derecho a ser oído) en el evento que el costo del respeto de la garantía sea mayor que la probabilidad del error si se niega la salvaguarda, multiplicado por la entidad de la pérdida si se materializa el error. Si se produce el caso contrario, entonces, debe concederse al ciudadano el derecho a ser oído por el órgano jurisdiccional ${ }^{9}$.

A partir del examen de la fórmula mencionada, y que materializa las exigencias y propósitos del Análisis Económico del Derecho, podríamos concluir que en su formulación, se ponderan debidamente los intereses involucrados en el resguardo del debido proceso, así como los criterios tendientes a la minimización de los costes sociales, por lo que la contradicción intuitiva antes indicada, no sería tal.

\section{LAS MEDIDAS CAUTELARES DESDE LA PERSPECTIVA DEL ANÁLISIS ECONÓMICO DEL DERECHO}

Sin pretender dar un concepto de tutela provisional, podemos señalar que la finalidad de la tutela provisional es la de un actuar temprano dentro del proceso de forma que el plazo necesario para el reconocimiento definitivo del derecho, no prive irreversiblemente de contenido al propio derecho, haciendo nula la posibilidad de su ejercicio. En términos más resumidos, la tutela provisional pretende la efectividad de la tutela jurisdiccional definitiva, dada la imposibilidad lógica y empírica de una simultaneidad temporal entre el inicio del proceso

\footnotetext{
7 Sin embargo, dicha fórmula considera la cuantía de los daños y gastos totales no de los daños y gastos adicionales o marginales, por lo que la suma total de las variables, no resulta completamente minimizada.

8 SChafer, Hans-Bernd y OTt, Claus. Manual de Análisis Económico del Derecho Civil. Madrid, España: Editorial Tecnos, 1991, p.109-111.

9 En base a tal análisis, Richard Posner concluye que el propietario de un automóvil abandonado debe ser notificado y recibir una oportunidad de audiencia ante el tribunal respectivo antes de que el automóvil sea retirado por una grúa y vendido como chatarra, mas no, si estamos frente a un propietario de un automóvil mal estacionado, precisamente porque en el primer caso es probable que el automóvil no estuviere abandonado, sino que descompuesto o robado, y como no se conoce dicha situación, el costo de la audiencia es moderado en relación con el valor del automóvil, y con la probabilidad alta de error en cuanto a decidir si existe o no abandono del vehículo. Lo que no ocurrirá con el caso del automóvil mal estacionado, ya que es fácil la constatación de dicha situación, disminuyéndose las probabilidades del error, existiendo en este caso, un alto costo asociado a la realización de una audiencia, toda vez que, la argumentación del propietario no pasará de justificaciones vanas que no podrán desvirtuar la infracción.
} 
y la decisión definitiva. En tal sentido, en el ámbito procesal civil, la tutela provisional tiene (en teoría) una extensión tan amplia como sea posible imaginar, refiriéndose: a todo medios de salvaguarda de dicha tutela definitiva dentro del curso del proceso.

La tutela cautelar opera bajo las exigencias del tiempo. Por lo mismo, y frente a la tardanza de los procesos judiciales ${ }^{10}$, la cautela constituye un instrumento a fin de afrontar la demora del proceso. Sin embargo, la expansión de la tutela cautelar en sus ámbitos de aplicación ha significado por contrapartida, la afectación de exigencias del debido proceso, tales como el derecho a la igualdad procesal y la bilateralidad de la audiencia. Es imposible pensar que la necesidad de obtener decisiones en un plazo razonable, se produce sin un sacrificio a la calidad del proceso y, correlativamente, a sus niveles de exactitud. Es así como es realista sostener que una tutela provisional esconde una desigualdad en el procedimiento y una disímil protección de los derechos de las partes. Se genera así una verdadera paradoja de garantías ${ }^{11}$, que manifiesta la existencia de intereses contrapuestos que, por una parte, exige celeridad cautelar y, por la otra, impone el respeto a ciertas ritualidades que favorecen el debido proceso.

Una de las maneras de poner fin a dicha paradoja viene dada por el Análisis Económico del Derecho Procesal, materializada en la denominada propuesta Posner-Leubsdorf ${ }^{12}$, la que otorga un sentido económico al parámetro de los cuatro factores desarrollado en la legislación norteamericana ${ }^{13}$, en relación a las medidas cautelares. Dicha fórmula se expresa como sigue:

$$
\mathrm{P}(\mathrm{D} \text { te })>(1-\mathrm{P}) \mathrm{Ddo}^{14}
$$

\footnotetext{
10 Peña GonZÁlez, Carlos. "Informe sobre Chile. Situación y políticas judiciales en América Latina”, en: Cuadernos de Análisis Jurídico, pp. 350-351. Santiago, Chile: Universidad Diego Portales, 1993.

11 Lo que es puesto de manifiesto por Francisco Ramos Romeu, cuando señala: "Este conflicto de intereses se traducirá en un conflicto de garantías en sede cautelar. Desde el punto de vista del solicitante, las medidas cautelares requieren celeridad, agilidad y flexibilidad de la Administración de Justicia, lo que en última instancia protege el derecho a la tutela judicial efectiva y el derecho a la efectividad de la tutela cautelar. Desde el punto de vista del demandado, la invasión de su esfera jurídica requiere que se le cite en condiciones adecuadas, que tenga una oportunidad para defenderse y contradecir los argumentos del demandante, lo que queda protegido por las garantías de audiencia y contradicción, la garantía de defensa y la igualdad de partes", en RAMOS ROMEU, Francisco. Las Medidas Cautelares Civiles. Análisis Jurídico-Económico. Barcelona, España: Editorial Atelier, 2006, p. 629.

12 LeubSDorf, John. "The Standard for Preliminary Injunctions", en: Harvard Law Review, 91, p. 525. Massachussets, Estados Unidos: Harvard University, 1978; Roland Machinery Co vs. Dresser Industries Inc. 749., f. 2D (7o. Cir. 1984) 7 p; y, POSNER, Richard, op. cit. (n.1), p. 520.

13 Los cuatro factores a considerar para conceder una medida cautelar en la legislación norteamericana son: (a) La existencia de un riesgo de daño irreparable para el demandante de no adoptarse la tutela provisional (the threat of irreparable harm to the Plaintiffs); (b) La probabilidad que el demandante obtenga un resultado favorable en el juicio (the probability that the Plaintiffs will succeed on the merits); (c) La comparación del riego de daño irreparable del demandante, con aquel riesgo de daño que la concesión de la medida cautelar ocasionará en las otras partes del juicio, y especialmente, en el demandado (the state of the balance between this harm and the injury that granting the injunction will inflict on other parties), y (d) la existencia de un interés público (whether it is in the public interest. WOLF, Arthur. "Preliminary Injunctions", en: Western New England Law Review. 7, p. 228. Massachussets, Estados Unidos: Western New England College, School of Law, 1984.

14 Donde P es la probabilidad de que el demandante gane en el juicio, y por tanto (1-P) es la probabilidad de que el demandado gane. Dte es el daño irreparable que sufrirá el demandante si no se otorga la medida cautelar, y D do, es el daño irreparable que sufrirá el demandado si se otorga la tutela provisional.
} 
De acuerdo a ella, debería concederse la prohibición preliminar, si y solo si, la proporción de las probabilidades de triunfo del demandante respecto de las del demandado supera la proporción del daño irreparable del demandado respecto del daño irreparable del demandante ${ }^{15}$.

Dicha fórmula pretende equilibrar los intereses contrapuestos, sobre el entendido económico que toda decisión genera costes/beneficios ${ }^{16}$. Sin embargo, la mencionada propuesta parte de premisas que necesitan ser explicitadas, a fin que se logre el objetivo buscado. En efecto, en el marco del parámetro propuesto, se supone que una concesión errónea de una medida cautelar va a generar perjuicios a la demandada y que, en algún momento posterior, dichos daños deben ser trasladados a quien deba soportarlos, en el evento que el demandado obtenga un resultado favorable. Por lo mismo, el régimen de responsabilidad va asociado ineludiblemente a la propuesta referida, ya que con su establecimiento se trasladan los perjuicios de la parte que los sufre a quien deba en definitiva, soportarlos (esto es, el demandante pernicioso). No obstante ello, el criterio Posner-Leubsdorf nada dice.

Adicionalmente, la fórmula mencionada guarda culpable silencio acerca de uno de los costes más relevantes asociados a la concesión de una medida cautelar y que son los costes sociales. En esta materia, ellos se materializan como daños sufridos por terceros o por el sistema judicial, que no son posibles de ser trasladados en el marco de un procedimiento tendiente a la determinación de la responsabilidad del causante del perjuicio. Así también, existen una serie de costos ( $A$ direct net loss of social welfare) que no pueden, siquiera, dar lugar a transferencias entre las partes, por lo que incluso cualquier mecanismo de responsabilidad resulta insuficiente ${ }^{17}$. Con todo, dichos costes existen y si se pretende considerar en el equilibrio de eficiencia implícito en la fórmula referida, la totalidad de los costes/beneficios que la medida

\footnotetext{
15 POSNER, Richard. op.cit. (n. 1), p. 520.

16 La contribución en ese sentido, proviene precisamente de Ronald Coase, quien en su publicación de 1960, en The Journal of Law and Economics de la Universidad de Chicago, titulada: "El problema del costo social", deja en claro que toda decisión jurídica de asignación de derechos significa un problema dual, ya que al beneficiar a $\mathrm{A}$, se está perjudicando a $\mathrm{B}$, frente a lo cual, y con miras a evitar el mal mayor, debe decidirse si se permite que A dañe a B, o bien que B dañe a A. A tal efecto, señala: "El problema que enfrentamos al manejar acciones que tienen efectos dañinos no es sencillanente restringir a los responsables de los mismos. Lo que debe decidirse es si la ganancia por evitar el daño es mayor que la pérdida que se sufriría de otro modo, como resultado de detener la acción que produce el daño. En un mundo donde hay costos de reordenar los derechos establecidos por el sistema legal, la justicia, en casos relativos a molestias, está tomando decisiones económicas sobre cómo han de emplearse los recursos (...). Pero la delimitación de derechos es también resultado de leyes. Aquí también hallamos pruebas de la aplicación de la naturaleza recíproca del problema. En tanto que las leyes se agregan a la lista de molestias, la acción es también tomada para legalizar lo que, de otro modo, serían molestias para el derecho consuetudinario. La clase de situaciones que los economistas están dispuestos a considerar como que requieren la acción correctiva del Gobierno son, en realidad, el resultado de la acción gubernamental. Tales acciones no son necesariamente desacertadas. Pero existe el peligro real de que la intervención extensiva del Gobierno en el sistema económico puede conducir a la protección de los responsables de los efectos dañinos" COASE, Ronald. "El problema del Costo Social”, en: Revista de Estudios Públicos, N o 45, p. 114. Santiago, Chile: Centro de Estudios Públicos, 1992.

17 GRISSKOPF, Ofer, y MEDINA, Barak. Repairing (the Doctrine of) Irreparable Harm: Economic Analysis of Preliminary Injunctions p. 2. <En línea>. [ Consulta el 5 de septiembre de 2010]. Disponible en World Wide Web:<http://works.bepress.com/ barak_medina/6]>,
} 
cautelar produce, ellos deben encontrar una cabida, por medio de una variable sujeta a control judicial.

Por lo mismo, podemos reformular la propuesta Posner-Leubsdorf, como sigue:

$$
\mathrm{P}(\mathrm{D} \text { te })>(1-\mathrm{P}) \mathrm{Ddo}+\mathrm{P}(\mathrm{D} \text { ter })
$$

En donde se agrega como variable a considerar el daño que la medida cautelar produce en terceros ( $\mathrm{D}$ ter), el que también es probabilístico $(\mathrm{P})$, ya que no toda tutela provisional va asociada al mismo.

El gran aporte de la fórmula mencionada, lo constituye el hecho de consagrar el daño probable que la medida produce en el demandado, ya que el interés de dicha parte, en cuanto al perjuicio consecuente a la adopción de una medida cautelar, no encuentra reconocimiento en nuestra legislación ${ }^{18}$.

\section{LA EFICACIA CUANTITATIVA Y CUALITATIVA, Y LA ONEROSIDAD CUANTITATIVA Y CUALITATIVA EN RELACIÓN AL PRINCIPIO DISPOSITIVO}

Ahora bien, para poder analizar la modificación de la cautela, en la lógica del presente trabajo, debemos indicar que la propuesta referida se encuentra sujeta a un examen de eficacia cuantitativa y cualitativa, así como de onerosidad cuantitativa y cualitativa. Lo que se busca es obtener la medida cautelar que satisfaciendo la fórmula referida, reduzca de mayor manera los costes sociales involucrados. De acuerdo a lo que ha acreditado Francisco Ramos

\footnotetext{
18 Algunos autores, como Juan Carlos Marín González (MARín, Juan Carlos. Las medidas cautelares en el proceso civil chileno doctrina, jurisprudencia y derecho comparado. Santiago, Chile: Editorial Jurídica, 2002, p. 216), ven en la proporcionalidad un criterio normativo que considera el interés del demandado de manera igualitaria a la consideración del interés del demandante. Sin embargo, ello no es así, la proporcionalidad solo significa que debe existir algún grado de adecuación entre la tutela provisional y la pretensión ejercida, de forma que, la clase de cautela que se obtenga sea apta para satisfacer una eventual tutela definitiva posterior. En otras palabras, se refiere al nivel de eficacia cualitativa de la tutela cautelar. Asimismo, exige una delimitación de la prohibición preliminar, en cuanto a que las medidas genéricas, no cumpliría con el principio de proporcionalidad, ya que a mayor generalidad mayor posibilidad de error en la adecuación provisional-definitiva. Según, Juan Carlos Marín, la proporcionalidad importa no solo dicho nivel de correlación y homogeneidad entre la tutela cautelar y la definitiva, sino que además, por medio de ella, debe resguardarse los intereses del sujeto pasivo, en cuanto a ponderar sus intereses. No obstante, considero que dicho argumento solo es correcto en un sentido débil, en cuanto a que, obviamente, aquella medida excesiva para los fines cautelares, excede la naturaleza de una medida propiamente provisoria, y en consecuencia, se transforma en un arma de presión ilegítima para el demandado. Así, por ejemplo, si se concede una medida precautoria de prohibición de celebrar actos y contratos sobre todo el patrimonio inmueble de una sociedad, por una deuda que no supera el valor de cualquiera de dichos bienes raíces, estaríamos sobrecautelando los derechos del demandante, y transformando la medida cautelar en un medio de presión para el sujeto pasivo. No obstante ello, extender el principio de proporcionalidad a la ponderación de los intereses de ambas partes, en términos de igualdad, significa superar ampliamente el sentido y alcance de dicho concepto, cuyo reconocimiento normativo encontramos en el artículo 298 del Código de Procedimiento Civil, cuya norma, en armonía con el interés del demandante, pretende limitar su interés cautelar a la pretensión ejercida en el juicio, sin que pueda de ella, derivarse ninguna ponderación a favor del demandado, sino aquella, que deriva de una prohibición de extralimitación cautelar.
} 
Romeu $^{19}$, la obtención de una solución eficiente en materia de contra cautela puede significar, incluso, la afectación de la eficacia cuantitativa y cualitativa de la medida propuesta y/o de la medida reformada.

La eficacia cuantitativa en materia de medidas cautelares, mide la cantidad de daño que la tutela provisional evita que se produzca en el demandante. Para poder denotar la eficacia cuantitativa de una medida, tenemos que partir de aquella cuantía que represente la parte de los daños no cubiertos por una medida cautelar (z). En consecuencia, la eficacia cuantitativa viene dada por:

$$
\text { Dte }-\mathrm{z}
$$

De lo anterior, se concluye que la medida cautelar sería óptima desde la perspectiva de la eficiencia cuantitativa, cuando:

$$
\text { P x Dte }>(1-p) \times \text { Ddo }+P \times D \text { ter })+P \times(\text { Dte-z })
$$

Esto es, cuando el daño probable que el demandante sufrirá de no adoptarse la medida es mayor que la suma del daño probable que sufrirá el demandado y terceros de adoptarse la medida cautelar y la cuantía probable de los daños que la medida evite.

De ello se deduce que una medida será óptima, desde un punto de vista de la eficiencia cuantitativa, aun cuando no se eliminen todos los daños que pueda sufrir el demandante, lo que se manifiesta en el producto de Dte $-\mathrm{z}$.

Sin embargo, la pregunta que surge es si acaso la sola consideración a la eficacia cuantitativa permite optar por aquella medida que reduzca de mayor forma y, de la manera más óptima posible, los costos sociales involucrados en la tutela cautelar. ¿Puede una propuesta centrada en la eficacia cuantitativa de la medida lograr que en la concesión de la tutela cautelar se opte por aquella medida que minimice en mayor medida los costos sociales?

La respuesta aparece como negativa. En efecto, el demandante al valorar qué medida solicitará solamente tomará en consideración aquellas medidas que logren compatibilizar de mejor manera los daños que desea cubrir, en relación con los posibles perjuicios a los que puede hacerse responsable. No tendrá en cuenta, si la medida que opta es aquella que reduce la sumatoria de los diferentes componentes que se incluyen en la cuestión cautelar.

Por lo mismo, y si queremos avanzar en dicho sentido, debemos hacer presente otros parámetros de eficiencia y onerosidad que podrían resultar deseable en materia cautelar. Así, encontramos: (a) la eficacia cualitativa que se refiere a la probabilidad de que, una vez adop-

19 Ramos RomeU, Francisco, op. cit. (n. 11), pp. 501-505. 
tada la medida, esta resulte eficaz, (b) la onerosidad cuantitativa referida a la cuantía de los daños que la medida podría generar en el demandado, y (c) la onerosidad cualitativa, que es el reflejo de la eficacia cualitativa, en el sentido de que a mayor efectividad de la medida en cuanto al logro de su fin, mayor es la onerosidad que sufre el demandado. A continuación, analizaremos los dos primeros parámetros, ya que el tercero, se desprenderá de lo que se dirá acerca de la eficacia cualitativa de la tutela.

La eficacia cualitativa de la tutela provisional se refiere a la probabilidad que, una vez adoptada dicha tutela, la misma resulte eficaz. Entenderemos que $(\mathrm{t})$ mide el grado de eficacia cualitativa de la medida, la que resultará óptima si es que:

$$
\text { P x Dte }>\{(1-p) \times \text { Ddo } \times \mathrm{t} \times(\mathrm{p} \times \mathrm{D} \text { ter })\}+\{(\mathrm{P} \times(1-\mathrm{t}) \times \mathrm{D} \text { te })\}
$$

Esto es, cuando el daño probable que el demandante sufrirá de no adoptarse la medida es mayor que la suma del producto que se obtiene del daño probable que sufrirá el demandado y terceros de adoptarse la medida cautelar multiplicado por la probabilidad de que ellos sufran un daño dada la eficacia de la medida, y la cuantía probable del daño que se le ocasiona al demandante por la no efectividad de la tutela provisional.

Si es el caso que el grado de eficacia cualitativa de la medida es igual o menor a 0 , nunca estaríamos en presencia de una medida óptima, porque ella nunca lograría ningún nivel de efectividad.

Por lo mismo, la eficacia cualitativa de la medida cautelar, encuentra su correlato normativo en el principio de proporcionalidad, en cuanto, la eficacia cualitativa mide que tan proporcional es la medida a los fines buscados por ella. En base a lo anterior, la medida cautelar debe tener algún nivel de proporcionalidad y, por lo tanto, debe reunir el siguiente requisito:

$$
\mathrm{T}>\mathrm{O}
$$

Asimismo, en miras a la obtención de un nivel óptimo, frente a diferentes medidas cualitativamente eficientes, debe optarse por la más eficaz de ellas, esto es, por la que consiga de mejor forma el fin buscado.

Al igual como ocurre con la eficacia cuantitativa, al demandante también le corresponde en el marco de un sistema dispositivo, optar por aquella medida que satisfaga de mejor manera, su expectativa de eficacia cualitativa. Y de la misma forma, tampoco se logra con el ejercicio de dicha opción, elegir la medida que reduzca de mayor manera los costos sociales involucrados en una tutela cautelar.

Para que ello ocurra, debemos considerar el parámetro de la onerosidad cuantitativa, esto es, de la cuantía de los daños que la medida puede generar en el demandado. Así, si 
tenemos la medida 1 que produce daños denotados por ( $\mathrm{D}$ do1) y la medida 2 que produce daños denotados por (D do2), se debe optar por (D do1), solo si:

$$
\text { Ddo } 1<\text { Ddo2 }
$$

Lo que en otros términos significa:

$$
\text { P } \times \text { Dte }>(1-p) \times D \text { do } 2+(p \times D \text { ter })>(1-p) \times D \text { do } 1+(p \times D \text { ter })
$$

Sin embargo, como resulta fácil constatar, el demandante a quien le compete, la solicitud de una medida cautelar, no tomará en cuenta, la cuantía de los daños que la medida pueda generar, si es el caso, que ella resulta óptima y, a la vez, eficaz cuantitativa y cualitativamente hablando.

De esta forma, si la medida solicitada cumple con la propuesta enunciada y aunque sea no óptima desde la mirada de la onerosidad cuantitativa (porque por ejemplo, ocasiona daños en $\mathrm{D}$ do2), ella deberá ser concedida, por mucho que exista una alternativa que reduzca de mayor medida los daños probables que la medida ocasione el demandado.

Para que ello ocurra, se debe limitar el principio dispositivo, y conceder al tribunal la facultad para modificar la medida cautelar solicitada por el demandante, siempre que exista una medida cautelar alternativa que reduciendo la onerosidad cuantitativa de ella, no perjudique la eficacia cuantitativa ni cualitativa de la tutela provisional (limitación débil a principio dispositivo).

Incluso, podría limitarse en mayor medida el principio dispositivo, en cuanto a modificar una medida cautelar solicitada, por aquella que tenga como finalidad la reducción de la mayor cantidad de costos sociales posibles, con prescindencia de si, con ello se afecta o no, la eficacia cualitativa y cuantitativa de la medida (limitación fuerte al principio dispositivo).

La eficacia, como hemos visto, exigiría adoptar esta última posición.

\section{LA REGULACIÓN NACIONAL DE LA CONTRA CAUTELA}

Ahora, debemos responder la pregunta acerca de cómo se encuentra regulada la contra cautela en nuestra legislación. La respuesta la encontramos en el artículo 301 del Código de Procedimiento Civil, que dispone: "Todas estas medidas son esencialmente provisionales. En consecuencia, deberán hacerse cesar siempre que desaparezca el peligro que se ha procurado evitar o se otorguen cauciones suficientes".

Tenemos, entonces, que el reemplazo de la cautela se encuentra regulada, a propósito de la provisionalidad de la medida cautelar, lo que significa que ella debe cesar siempre que 
los requisitos que permitieron su concesión dejen de existir luego de su otorgamiento, o bien, que el peligro implícito en la tutela provisional, sea reemplazo por una contra cautela suficiente.

La lógica de aplicación de la contra cautela, supone que necesariamente ella debe ser ofrecida y probada en su suficiencia, por el demandado, o bien, por ambas partes de común acuerdo. En consecuencia, rige a su respecto, plenamente el principio dispositivo, no siendo posible que el juez, actuando de oficio, ordene el reemplazo de la cautela por una caución suficiente. La regla del artículo 10 inciso 1 del Código Orgánico de Tribunales se impone de manera absoluta.

Ahora bien, como sabemos el ámbito de la justicia civil, existe en nuestro país, un movimiento de reforma que se inició el año $2004^{20}$ y que ha dado como resultado la publicación de un Anteproyecto de Código de Procedimiento Civil. En dicho texto prelegislativo, se regula en el artículo 172 inciso 2, bajo el acápite de: “Ámbito de Aplicación”, la siguiente regla: "Estas medidas no podrán ser decretadas de oficio por el tribunal, pero este podrá conceder una medida diversa de la requerida por el actor si, resguardándose de igual modo su pretensión, fuere menos gravosa y perjudicial para el demandado".

Dicha norma modifica el estatuto de la contra cautela actual, ya que, si bien reitera como regla general el principio dispositivo, lo aminora a los efectos de permitir que el juez pueda conceder una medida distinta de la requerida, si es el caso, que teniendo su misma eficacia cuantitativa, fuera menos onerosa cuantitativamente. En consecuencia, estamos en presencia de una norma que restringe en un sentido débil el principio dispositivo, de acuerdo a lo señalado en el acápite anterior. Ello genera una situación superior a Pareto ${ }^{21}$, en comparación con el estado actual de la cuestión ya que si existe una medida alternativa a la propuesta que sea menos onerosa cuantitativamente, corresponderá optar por ella.

Sin embargo, la solución adolece de problemas. En primer lugar, la posibilidad de reforma está establecida como una facultad del tribunal. Y en segundo lugar, solo comprende un supuesto de reforma, a saber, aquel donde se escoge aquella medida que teniendo una mis-

\footnotetext{
20 Efectivamente, dentro de este marco el Ministerio de Justicia del gobierno del ex Presidente de la República Ricardo Lagos Escobar, estableció como una de sus prioridades el inicio de los estudios destinados a proveer al país de una legislación procesal civil moderna. Para lograr este objetivo se firmó con fecha 1 de octubre del año 2004 un Convenio marco entre el Ministerio de Justicia y la Facultad de Derecho de la Universidad de Chile durante el segundo semestre del año 2004. El convenio estableció que una Comisión integrada por profesores del Departamento de Derecho Procesal y abogados asesores del Ministerio de Justicia elaborarían unas "Bases para un nuevo sistema procesal civil en Chile". Luego, las citadas bases se discutirían en un foro ampliado para su aprobación definitiva. La Comisión designada en conjunto por el Ministerio de Justicia y la Facultad de Derecho de la Universidad de Chile estuvo integrada por los profesores de Derecho Procesal de esa casa de estudio, Cristián Maturana Miquel (Presidente), Juan Agustín Figueroa Yávar; Raúl Tavolari Oliveros, Raúl Núñez Ojeda, Juan Carlos Marín González, Davor Harasic Yacsic y de los abogados asesores del Ministerio de Justicia señores Rodrigo Zúñiga Carrasco y Rodrigo Romo Labich; actuando como Secretarios de la Comisión los señores Matías Insunza Tagle y Cristóbal Jimeno Chadwick.

21 Siendo el estado anterior, sobre el cual se valora el cambio de escenario, aquella medida cautelar propuesta por el demandante.
} 
ma eficacia cuantitativa genera menos onerosidad de dicha calidad. Pero no abarca supuestos en donde, por ejemplo, se afecte la eficacia cuantitativa de la medida sugerida, y se opte por aquella cautela que reduzca los costos totales involucrados. Por lo mismo, la regulación prelegislativa no establece una normativa, a estos efectos, completamente eficiente, aun cuando se aproxima a ella.

Lo anterior, y recurriendo a lo analizado en el acápite precedente, se comprobará con el siguiente ejemplo. Supongamos una situación en donde se ha concedido una medida cautelar (M 2), y se propone por el demandado su reemplazo por una nueva medida cautelar (M 1). Adicionalmente, convengamos que ambas medidas consiguen de igual forma el mismo fin tutelar, por lo tanto, ambas medidas producen idéntica eficacia cualitativa. Para poder desarrollar el ejemplo debemos considerar los siguientes valores, a saber:

D te (Daño que la medida ocasiona al demandante en caso de no concederse la cautela) $=$ $\$ 250$

$\mathrm{D}$ do (Daño que la medida ocasiona al demandado en caso de concederse la cautela) $=\$ 90$

$\mathrm{D}$ ter (Daño que la medida ocasiona a terceros y al sistema judicial en caso de concederse la cautela $)=$ En el caso de la Medida 1: \$10, y en el caso de la Medida 2: \$ 5

$\mathrm{P}$ (Probabilidad que el demandante obtenga un resultado favorable ${ }^{22}$ ) $=$ En el caso de la Medida 1: 60\% (0.6), y en el caso de la Medida 2: 40\% (0.4)

(1-p) (Probabilidad que el demandado obtenga un resultado favorable) $=$ En el caso de la Medida 1: 40\% (0.4), y en el caso de la Medida 2: 60\% (0.6)

$\mathrm{Z}$ (Daños para el demandante que la medida evita) = En el caso de la Medida 1: \$200, y en el caso de la Medida 2: \$210.

Si aplicamos la fórmula para determinar la eficacia cuantitativa de la medida ${ }^{23}$, tenemos que los daños que se producen para el demandante se obtienen de:

$$
(1-p) \times(D \text { te }-Z)
$$

Lo que en el caso de la Medida 1, significa un coste por: $\$ 20(0,4 \times 50)$. Y en el caso de la Medida 2, significa un coste por: \$ $24(0,6 \times 40)$.

Por su parte, los daños que se producen al demandado y a terceros se obtienen de:

\footnotetext{
22 Para los efectos de este ejemplo (P) también expresa la variable probabilística de los daños que la medida cautelar ocasiona en terceros.

23 P x Dte $>(1-\mathrm{p}) \times \mathrm{Ddo}+\mathrm{P} \times \mathrm{D}$ ter $+\mathrm{P} \times($ Dte-z).
} 


$$
(1-p) \times \text { Ddo }+(P \times D \text { ter })
$$

Lo que en el caso de la medida 1, significa un coste por: $\$ 42(36+6)$, y en el caso de la medida 2 , significa un coste por: $\$ 44(42+2)$.

Ambas medidas son eficientes de acuerdo a la fórmula:

$$
\text { P x Dte }>(1-p) \times \text { Ddo }+ \text { P x D ter }+ \text { P } \times(\text { Dte-z })
$$

Toda vez que en ambos casos los daños derivados de su adopción ( $\$ 62$ para la medida 1, y: \$ 68 para la medida 2), son menores a los derivados de su no otorgamiento (\$ 150 para la medida $1, \mathrm{y}: \$ 100$ para la medida 2).

Por lo mismo, ambas medidas deberían concederse por el tribunal. Con todo, la que reduce en mayor medida los costos totales del sistema cautelar, es la medida 1, ya que supone un ahorro de: \$ 6 respecto de su alternativa. Por lo mismo, debería optarse (y la legislación propender a ella) siempre por la que hemos denominado medida 1.

Sin embargo, si seguimos la regla del artículo 174 inciso 2 del Anteproyecto de Código de Procedimiento Civil, no debería concederse la medida 1, no obstante, constituir el óptimo en la materia, toda vez que, dicha cautela, tiene una menor eficacia cuantitativa que la medida 2, ya que, frente a ella, evita menos daños para el demandante (\$ 50 versus \$ 40), y como no es posible, entender que la medida 1 , resguarda de mejor manera la pretensión del actor, entonces, no será posible la reforma a la cautela, y con ello, alcanzar el óptimo desarrollado.

Con lo anterior, se demuestra la insuficiencia de la propuesta prelegislativa, desde la eficiencia, y se hace necesario de lege ferenda, reformular la legislación sobre contra cautela a fin de propender a lo aquí indicado.

\section{CONCLUSIÓN}

De acuerdo a lo señalado en el presente trabajo podemos concluir lo siguiente:

5.1. El Análisis Económico del Derecho, a pesar de su propuesta tendiente a la eficiencia, no vulnera las exigencias que impone el debido proceso legal y otorga fórmulas que satisfacen debidamente dichos resguardos.

5.2. En materia de medidas cautelares, el modelo paradigmático que propone el Análisis Económico del Derecho es el denominado criterio Posner-Leubsdorf, el que si bien permite dar respuestas correctas a la paradoja de garantías que subyace al problema cautelar, es con todo, insuficiente, al no contemplar como variable aquellas que derivan de los costos sociales envueltos en el otorgamiento de una medida cautelar. 
5.3. Ahora bien, si aplicamos el criterio Posner-Leubsdorf reformulado al análisis de la reforma de la medida cautelar, desde la perspectiva de la eficacia y onerosidad cuantitativa y cualitativa, tenemos que la solución eficiente es aquella que, satisfaciendo el criterio señalado, reduce de mayor manera los costos totales involucrados en la tutela cautelar.

5.4. Nuestra legislación procesal actual, imbuida en el principio dispositivo, no satisface dicho estándar. Por su parte, la legislación prelegislativa contenida en el Anteproyecto de Código de Procedimiento Civil, si bien, constituye un estado normativo superior en términos de Pareto a la legislación actual, tampoco permite la obtención del óptimo aplicable a la contra cautela, otorgando un valor desmedido a la eficacia cuantitativa de la tutela provisional.

5.5. Para poder llegar a dicho óptimo, debemos dotar al juez, de facultades suficientes para modificar una medida cautelar que no cumpla con dicho nivel de eficiencia, aun cuando con ello, afectemos el principio dispositivo que rige nuestro sistema procesal.

\section{REFERENCIAS BIBLIOGRÁFICAS}

COASE, Ronald. "El problema del Costo Social", en: Revista de Estudios Públicos. [ Reproducido de The American Economic Review, Vol. 64 No 2 (1974), su traducción cuenta con la debida autorización]. No 45. Santiago, Chile: Centro de Estudios Públicos, 1992.

Cooter, Robert y Ulen, Thomas. Derecho y Economía. México DF, México: Fondo de Cultura Económica, 1998.

GrissKopf, Ofer, y MedinA, Barak. Repairing (the Doctrine of) Irreparable Harm: Economic Analysis of Preliminary Injunctions. <En línea> [Consulta el 5 de Septiembre de 2010]. Disponible en World Wide Web: $<$ http://works.bepress.com/barak_medina/6>.

LEUBSDORF, John. “The Standard for Preliminary Injunctions”, en: Harvard Law Review, 91. Massachussets, Estados Unidos: Harvard University, 1978.

MARÍn, Juan Carlos. Las medidas cautelares en el proceso civil chileno (doctrina, jurisprudencia y derecho comparado). Santiago, Chile: Editorial Jurídica, 2002.

Nogueira AlCalÁ, Humberto. El debido proceso en la Constitución y el sistema interamericano. Santiago, Chile: Editorial Librotecnia, 2007.

NúNEEZ Ojeda, Raúl. "El sistema de recursos procesales en el ámbito civil en un estado democrático deliberativo", en: Revista Ius et Praxis, v. 14, No 1. Talca, Chile: Universidad de Talca, 2008.

PEÑA González, Carlos. "Informe sobre Chile. Situación y políticas judiciales en América Latina”, en: Cuadernos de Análisis Jurídico. Santiago, Chile: Universidad Diego Portales, 1993.

POLINSKY, Mitchell. Introducción al Análisis Económico del Derecho. Barcelona, España: Editorial Ariel, 1985.

Posner, Richard. El análisis económico del Derecho. México DF, México: Fondo de Cultura Económica, 1992.

Ramos Romeu, Francisco. Las Medidas Cautelares Civiles. Análisis Jurídico-Económico. Barcelona, España: Editorial Atelier, 2006.

RoEmer, Andrés. Introducción al Análisis Económico del Derecho. México DF, México: Fondo de Cultura Económica, 1994. 
Nicolás Carrasco Delgado / A contra cautela. Una mirada desde el análisis económico del derecho procesal

SCHAFER, Hans-Bernd y OTt, Claus. Manual de Análisis Económico del Derecho Civil. Madrid, España: Editorial Tecnos, 1991.

TARUfFo, Michelle. La prueba de los hechos. Milán, Italia: Trotta, 2002.

Wolf, Arthur. "Preliminary Injunctions", en: Western New England Law Review. 7. Massachussets, Estados Unidos: Western New England College, School of Law, 1984. 